\title{
A Cross Sectional Survey on the Knowledge and Attitude towards the Use of Multivitamin Products among the Students of a Medical University in the U.A.E
}

Rina Rosalia, Sarah Panjwani, Asma Abdillahi Ali, Mohammed Muthana Hameed Al Hayali, Ahmad Mohammed Alahmad, Annie Shirwaikar*, Arun Shirwaikar

College of Pharmacy, Gulf Medical University, Ajman, UAE.

\begin{tabular}{l} 
ARTICLE INFO \\
\hline Article history: \\
Received on: $23 / 06 / 2017$ \\
Accepted on: $25 / 07 / 2017$ \\
Available online: $30 / 08 / 2017$ \\
\hline Key words: \\
Multivitamin, Multivitamin \\
Products, Anemia, Adverse \\
Effects.
\end{tabular}

\section{ARTICLE INFO}

Accepted on: 25/07/2017

Effects.

\begin{abstract}
Background and Objective: The consumption of multivitamin products for their benefits towards maintenance of health has often been debated upon. This study attempts to assess the knowledge and attitude of the students of a medical university towards the use of multivitamin products.

Materials and Methods: A descriptive cross-sectional questionnaire based study was conducted on 319 student participants of a medical university in the U.A.E. Data was analyzed using SPSS version 22 and Pearson Chi Square Test. Results: Among the 319 participants in the survey, $132(41.6 \%)$ were <20 years and $185(58.4 \%)$ were $\geq 20$ years. Pearson Chi-Square Test identified a statistically significant association between the participants' knowledge of multi vitamin products and their age $(\mathrm{p} \leq 0.001)$ and knowledge of multi vitamin products was found to be directly proportional to the age of the students. However, no significant association was found between the use of multivitamins and the students' region of origin, living status and BMI. Conclusion: It was observed that as the students progressed through the years in the medical university, they became more informed about the uses, benefits as well as the adverse effects associated with multivitamins.
\end{abstract}

\section{INTRODUCTION}

The consumption of multivitamin products has increased substantially in the last few years and it is reported that around 20 to $30 \%$ of the population of developed countries take multivitamin supplements regularly (Kaur and Sekhri, 2014; McNaughton et al., 2005; El-Kadiki and Sutton, 2005). In the present world, people who lead a busy life, very often fail to consume a balanced diet. People who skip their meals due to lack of time to care for their health as well as the sick and elderly who have difficulty in consuming normal food, often use these products (El-Kadiki and Sutton, 2005; Sebastian et al., 2007). The educated and many health conscious individuals, often compensate their vitamin deficiencies with such products. (El-Kadiki and Sutton, 2005; Munro and Danford, 1989).

* Corresponding Author

Email: shirwaikarannie@gmail.com, Phone: 00971-55-3105746 and Sekhri, 2014) In addition, changes in economic status are known to cause alteration in food habits. In order to compensate nutritional deficiency, consumption of multivitamin supplements is practiced Many studies have attempted to evaluate the true benefits of these multivitamin supplements. The results of a few large scale randomized controlled trials, indicate that multivitamin supplements are not effective in majority of the population. In a trial conducted amongst 14,641 subjects in the United States of America, it was found that daily consumption of multivitamin supplements did not lessen the incidence of cardiovascular events like stroke or myocardial infarction (Kaur and Sekhri, 2014; Kamangar and Emadi, 2012; Sesso et al., 2012). In a study conducted on elderly people to assess the effectiveness of multivitamin supplements in decreasing the frequency of infections and improving their immune system, it was reported that multivitamins did help in reducing the average number of days spent with infection per year (El-Kadiki and Sutton, 2005). 
In addition, there has been much evidence supporting the beneficial effects of using folic acid and iron supplements during pregnancy to prevent neural tube defects and anemia respectively (Kaur and Sekhri, 2014; Bender, 2002). Also, the use of ascorbic acid (vitamin C) has been reported to reduce the duration of common colds. In a study conducted on the efficacy of ascorbic acid in preventing and treating colds which involved 11,306 participants, it was found that Vitamin $\mathrm{C}$ did help in reducing the episodes of cold considerably (Hemilä and Chalker, 2013). However other studies report that the evidence of the benefits of multivitamin supplements is insufficient and this is causing growing concern in the healthcare field (El-Kadiki and Sutton, 2005; Bender 2002; Fawzi and Stampfer, 2003). Multivitamin supplements, when taken in excess, may create unexpected health problems.

Multivitamin overdose happens when a person knowingly or unknowingly takes more than the normal recommended dose of multivitamin supplements. In this situation, they may develop varying symptoms such as frequent urination and increased urine output, photosensitivity, dry, cracking lips, myalgia, general malaise, itching, constipation, weight loss, appetite loss etc. (U.S. National Library of Medicine, 2015).

Some studies report that the excessive use of some vitamins can increase the risk and incidence of certain types of cancer (Kamangar and Emadi, 2012; U.S. National Library of Medicine, 2015). Hence, it is quite evident that although multivitamins may have numerous health benefits, consumption in excess can pose side effects (Kaur and Sekhri, 2014; Sebastian et al., 2007). The present study is an attempt to assess the knowledge and attitude of university students, a stratum of contemporary society, towards the responsible and appropriate use of multivitamin products.

\section{MATERIALS AND METHODS}

\section{Research design}

A descriptive cross-sectional research design was undertaken to determine the knowledge and attitude towards the use of multi-vitamin products among the students of a medical university in the UAE.

\section{Study settings}

The survey was conducted within the premises of the medical university over a period of 3 months from September to November 2015.

\section{Sample}

The study was a population study in which the whole population of consenting students studying in the university participated.

\section{Inclusion criteria}

- $\quad$ Both males and females

- Students registered in the University
- Students aged 18 and above

- Students willing to participate

\section{Study instrument and validation}

A self- administered questionnaire including both open ended and closed ended questions was used as the study instrument. The questionnaire addressed the following:

1.Socio-demographic factors

2.Knowledge, practice and attitude towards the multivitamin products.

The questionnaire was validated by experts and by a preliminary pilot study to determine feasibility of the study and question clarity before commencement of the study. Data from the pilot study was not included in the final results.

\section{Ethical issues}

Ethical approval was obtained from the University Ethics committee before commencement. Only those who signed written consents were permitted to participate in the study. Anonymity and confidentiality of all participants were ensured.

\section{Data Analysis}

Data was first entered into an Excel sheet and then analyzed by SPSS version 22. Chi square test was used to determine the association between the determinants. A statistical significance level of $\mathrm{p} \leq 0.05$ was used to determine the association between variables.

\section{RESULTS}

The socio-demographic characteristics of study participants Vs the Use of multivitamins are depicted in Table 1.Among the 319 participants of the study, 2, 60, 25 and 11 student participants did not report their age, region of origin/ethnicity, BMI and their living status respectively. Multivitamin supplements were used by $41.6 \%$ of age group $<20$ years as compared to $58.4 \%$ used by those $\geq 20$ years. They belonged to different health science programs of the university and were of different ethnicities.

Though the number of participants from the Western Pacific region, European region and Americas were just two, five and four respectively, these regions reported the maximum percent utilization of multivitamins i.e. Western Pacific region (100\%), European region (80\%) and Region of Americas (75\%) Lowest multivitamin utilization was reported among the S. East Asians (44.6\%).

Using Pearson Chi-Square Test, a statistically significant association was found between the participants' use of multi vitamin products and their age $(\mathrm{p} \leq 0.001)$. The utilization of multivitamin products increased with the age of the students. There was no significant association between the utilization of multivitamin products with the living status and the BMI of the participants. Figure 1 depicts the distribution of participants who were familiar with multivitamins. Among the 319participantsof the study, 
majority i.e. 301 (94.4\%) reported to have heard of multi-vitamin products while only $18(5.6 \%)$ said that they had not heard of them. Their source of information about multivitamin products, as depicted in Fig. 2, was found to be predominantly their parents
(53.7\%), followed by the internet (49.9\%), doctors (45.5\%) and the media $(41 \%)$. A relatively small percentage of $14.6 \%$ and $8.6 \%$ reported their source of multivitamin information from the university and other sources respectively.

Table 1: Socio - Demographic Characteristics of Student Participants (N=319) Vs Use of Multivitamins.

\begin{tabular}{|c|c|c|c|c|c|c|}
\hline \multirow{2}{*}{\multicolumn{2}{|c|}{ Socio-demographic Characteristics }} & \multicolumn{4}{|c|}{ Use of multivitamins } & \multirow{3}{*}{ p value } \\
\hline & & \multicolumn{2}{|c|}{ Yes } & \multicolumn{2}{|c|}{ No } & \\
\hline & & No. & $\%$ & No. & $\%$ & \\
\hline \multirow[t]{2}{*}{ Age in years ${ }^{*}$} & $<20$ years & 47 & 35.6 & 85 & 64.4 & \multirow[t]{2}{*}{$\leq 0.001$} \\
\hline & $\geq 20$ years & 108 & 58.4 & 77 & 41.6 & \\
\hline \multicolumn{2}{|l|}{ Not Reported } & \multicolumn{5}{|c|}{2} \\
\hline \multirow[t]{6}{*}{ Region } & African Region & 22 & 46.8 & 25 & 53.2 & \multirow{6}{*}{$\begin{array}{c}\text { Not } \\
\text { Significant }\end{array}$} \\
\hline & Region of Americas & 3 & 75.0 & 1 & 25.0 & \\
\hline & South-East Asia Region & 29 & 44.6 & 36 & 55.4 & \\
\hline & European Region & 4 & 80.0 & 1 & 20.0 & \\
\hline & Eastern Mediterranean & 68 & 50.0 & 68 & 50.0 & \\
\hline & Western Pacific Region & 2 & 100.0 & 0 & 0.0 & \\
\hline \multicolumn{2}{|l|}{ Not Reported } & \multicolumn{4}{|c|}{60} & \\
\hline \multirow[t]{4}{*}{ BMI } & Underweight $(<18.45)$ & 22 & 52.4 & 20 & 47.6 & \multirow[t]{4}{*}{ Not Significant } \\
\hline & Normal (18.45-24.99) & 88 & 48.4 & 94 & 51.6 & \\
\hline & Overweight (25-29.99) & 30 & 54.5 & 25 & 45.5 & \\
\hline & Obese $(>=30)$ & 9 & 60.0 & 6 & 40.0 & \\
\hline \multicolumn{2}{|l|}{ Not Reported } & \multicolumn{4}{|c|}{25} & \multirow{3}{*}{ Not Significant } \\
\hline \multirow[t]{2}{*}{ Living status } & Living alone/ hostel & 48 & 53.3 & 42 & 46.7 & \\
\hline & With family & 105 & 48.2 & 113 & 51.8 & \\
\hline \multicolumn{2}{|l|}{ Not Reported } & \multicolumn{4}{|c|}{11} & \\
\hline
\end{tabular}

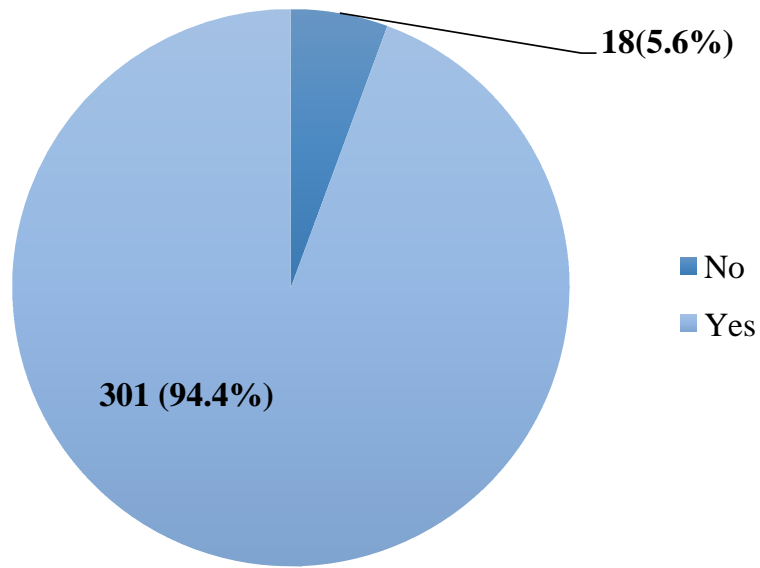

Fig. 1: Familiarity of Students with Multivitamins.

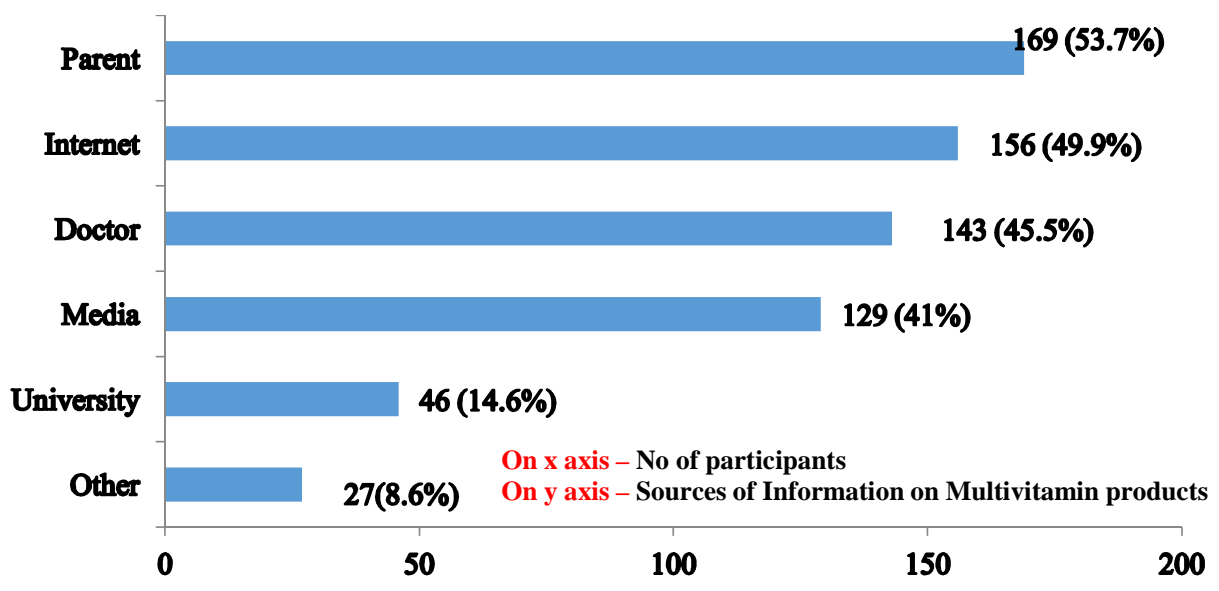

Fig. 2: Source of Information on Multivitamin Products. 


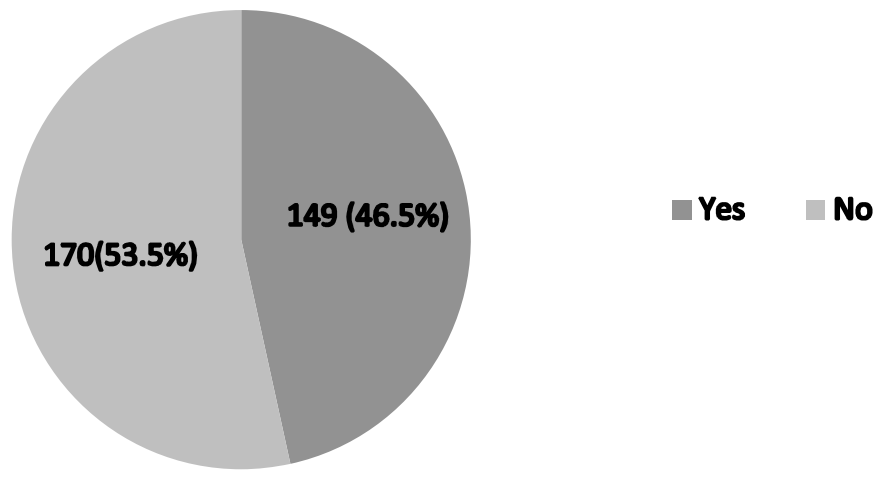

Fig. 3: Distribution of the Use of Multivitamin Products.

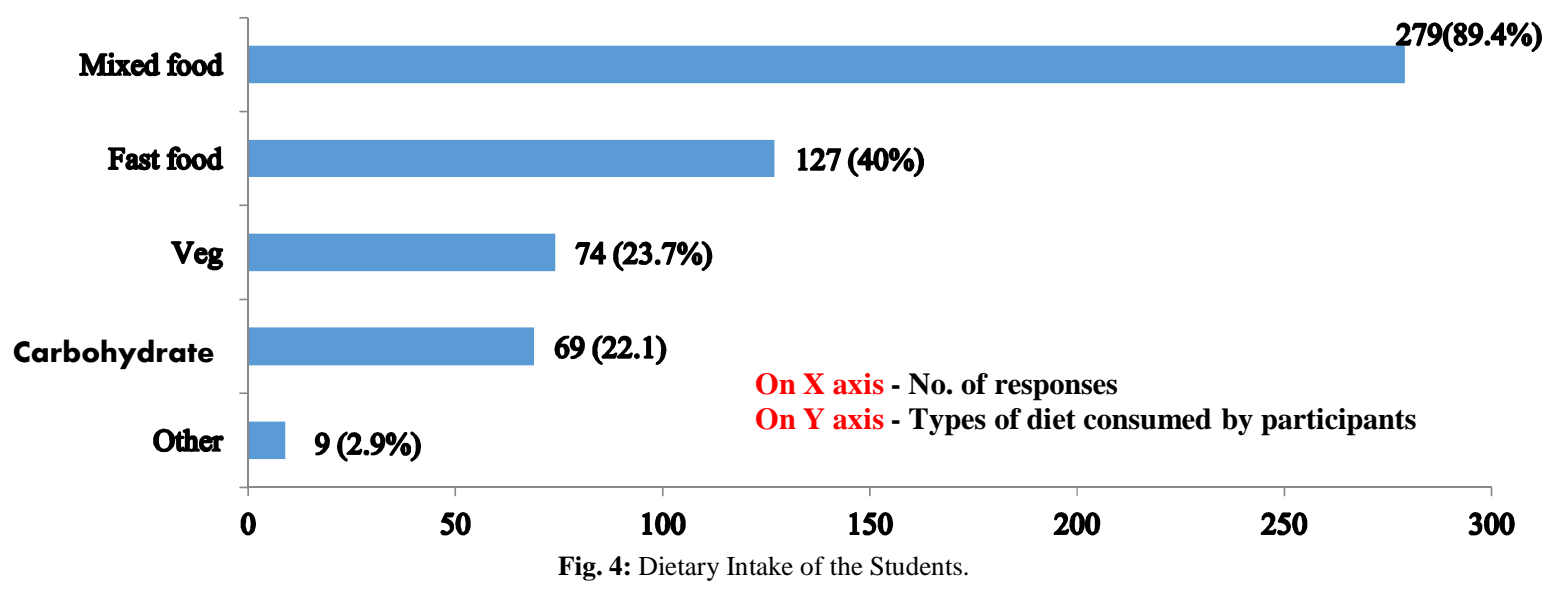

Total responses exceed $100 \%$ because of multiple responses to each item

On further analysis of the use of multivitamins, as depicted in figure 3, it was identified that among the 319 participants, 149 (46.5\%) reported to have used them while 170 $(53.5 \%)$ had not.

The distribution of the dietary intake of the students is given in Figure 4. On investigating the dietary habits of the participants, it was observed that the vast majority of the students consumed a mixed diet (89.4\%) followed by fast food (40\%). Only a minority of $23.7 \%$ and $22.1 \%$ participants consumed diets with vegetables $(23.7 \%)$ and carbohydrates $(22.1 \%)$ respectively.

\section{The total number of responses exceeds $100 \%$ due to the} multiple responses given by each participant

The source of influence that determined the use of multivitamins by the participants is given in Table 2 . Of the 319 participants, $88(27.6 \%)$ reported that their physicians had recommended multivitamin products for varying medical conditions while 73 participants stated that multivitamin products were recommended to them by their peers. The various reasons for the consumption of multivitamins are given in Table 3. Out of 88 participants who reported that they had used multivitamins based on their physician's recommendation, only 60 reported the reason behind their use while the remaining 28 either did not report or stated that they could not recall the reason for their use of the products.

Table 2: Source of Influence on the Use of Multivitamins by Students $(\mathrm{N}=319)$.

\begin{tabular}{ccccc}
\hline Medical Advice & & Number & Percentage (\%) & Total \\
\hline \multirow{2yyyn}{*}{$\begin{array}{c}\text { Has your doctor } \\
\text { recommended them? }\end{array}$} & No & 231 & 72.4 & 319 \\
\cline { 2 - 4 } & Yes & 88 & 27.6 & \\
\hline Peer Influence & & Number & Percentage (\%) & Total \\
\hline $\begin{array}{c}\text { Friends advised to } \\
\text { use multivitamins }\end{array}$ & No & 246 & 77.4 & 319 \\
\cline { 2 - 4 } & Yes & 73 & 22.6 & \\
\hline
\end{tabular}

Table 3: Reasons for Consumption of Multivitamin Products ( $N=60)$.

\begin{tabular}{lcc}
\hline Reasons for Consumption & No. & \% \\
\hline Unable to concentrate & 2 & 2.7 \\
Fever & 3 & 4.1 \\
Anemia & 11 & 15.1 \\
Vitamin D deficiency & 18 & 24.7 \\
Migraines & 1 & 1.4 \\
Lack of appetite & 3 & 4.1 \\
Low weight & 1 & 1.4 \\
B 12 deficiency & 1 & 1.4 \\
Weakness & 6 & 8.2 \\
Diabetes & 1 & 1.4 \\
Malnutrition & 4 & 5.5 \\
Health problems & 2 & 2.7 \\
Vitamin deficiency & 6 & 8.2 \\
Morning allergies & 1 & 1.4 \\
\hline
\end{tabular}


As illustrated in Figure 5, it was found that most students [106 (74.6\%)] who used multivitamin products obtained them from a pharmacy in UAE while $30(21.1 \%)$ participants reported that they bought the products from their home countries. A relatively small number of students [8 (5.1\%) and 5(3.5\%)] reported that they obtained the products by ordering online and from gymnastic centers respectively. A very minute percentage of participants $[5(3.5 \%)]$ stated that they used natural/alternative medicine for vitamin supplementation and that they procured this from homeopathic and ayurvedic centers.

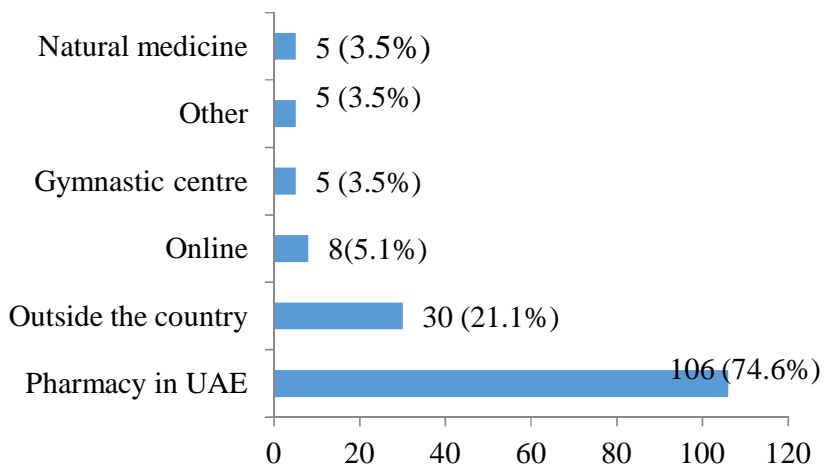

Fig. 5: Source of Multivitamins among student participants

Table 4 shows the commonly purchased brand of multivitamin products within the UAE. "Now Daily Vits" was found to be the most popular brand among the participants (33.1\%) while the least used brand was found to be "Dynamisan" $(3.3 \%)$.

Table 4: Most Commonly Used Brands of Multivitamin Products among Students $(\mathrm{N}=142)$

\begin{tabular}{lcccc}
\hline \multicolumn{1}{c}{ Brand } & No. & \% & No. & No \\
\hline Centrum & 34 & 28.1 & 87 & 71.9 \\
NOW Daily Vits & 40 & 33.1 & 81 & 66.9 \\
Nature made & 32 & 26.4 & 89 & 73.6 \\
Dynamisan & 4 & 3.3 & 117 & 96.7 \\
Others & 32 & 26.4 & 89 & 73.6 \\
\hline
\end{tabular}

Table 5: Reasons for Choosing a Multivitamin Product (N=149).

\begin{tabular}{lcccc}
\hline & \multicolumn{3}{c}{ Yes } & \multicolumn{2}{c}{ No } \\
\cline { 2 - 5 } Reason & No. & \% & No. & \% \\
\hline Affordable & 37 & 27.2 & 99 & 72.8 \\
Provides 100\% Daily Vitamin Value & 26 & 19.1 & 110 & 80.9 \\
Purity of Ingredients & 42 & 30.9 & 94 & 69.1 \\
Other & 40 & 29.4 & 96 & 70.6 \\
Designed for specific age/sex group & 16 & 11.8 & 120 & 88.2 \\
\hline
\end{tabular}

The reasons for participant choice of varying Multivitamin brands are given in Table 5. Of the 149 students who used multivitamins, $42(30.9 \%)$ said that they chose a product based on their belief that its ingredients were pure, while 37 (27.2\%) participants stated that their choice was based on affordability. The remaining 26 (19.1\%) and16 (11.8\%) participants claimed that their choice of the product was based on their belief that it provides complete i.e. $100 \%$ daily vitamin value and because it was designed for their specific age or sex group.
The total number of responses exceeds $100 \%$ due to the multiple responses provided by the participants for each item.

Of the participants who consumed multivitamin products (149), only $24(17.1 \%)$ had experienced adverse effects on taking the product while $116(82.9 \%)$ reported no complications. The remaining 9 did not answer the question. The most common side effect experienced by participants on using multivitamin products was stomach pain $(41.7 \%)$ followed by headache $(20.8 \%)$. Few (16.7\%) participants experienced side effects such as constipation, dizziness, diarrhea, dry mouth and indigestion. Only a minimal group of $8.3 \%$ participants experienced restlessness and insomnia. Table 6 depicts the side effects reported by the participants of the study. The total number of responses for the side effects section was 43 as some of the participants claimed to have experienced more than one side effect during the time of their multivitamin consumption.

Table 6: Side effects associated with the use of Multivitamin Products (N= 43).

\begin{tabular}{lcccc}
\hline & \multicolumn{2}{c}{ Yes } & \multicolumn{2}{c}{ No } \\
\hline Side effect & No. & \% & No. & \% \\
\hline Stomach pain & 10 & 41.7 & 14 & 58.3 \\
Constipation & 4 & 16.7 & 20 & 83.3 \\
Restlessness & 2 & 8.3 & 22 & 91.7 \\
Insomnia & 2 & 8.3 & 22 & 91.7 \\
Dizziness & 4 & 16.7 & 20 & 83.3 \\
Diarrhea & 4 & 16.7 & 20 & 83.3 \\
Dry mouth & 4 & 16.7 & 20 & 83.3 \\
Headache & 5 & 20.8 & 19 & 79.2 \\
Blurred vision & 3 & 12.5 & 21 & 87.5 \\
Other & 1 & 4.2 & 18 & 75.0 \\
Indigestion & 4 & 16.7 & 20 & 83.3 \\
\hline
\end{tabular}

Investigation of the participants' attitude towards multivitamins (See Table 7) revealed that among 319 participants, $283(89 \%)$ believed that intake of a balanced diet was best to maintain a healthy lifestyle; 238 (74.8\%) believed that multivitamin products are effective in promoting good health; 195 $(61.3 \%)$ participants reported that they would recommend the use of multivitamin products to others.

Table 7: Attitude of Respondents towards the Use of Multivitamin Products (N=319).

\begin{tabular}{lccccc}
\hline Attitude & \multicolumn{3}{c}{ Yes } & \multicolumn{2}{c}{ No } \\
\cline { 3 - 6 } & No. & \% & No. & \% \\
\hline Recommend people to use & 195 & 61.3 & 123 & 38.7 \\
Believe they are effective & 238 & 74.8 & 80 & 25.2 \\
Consumption of healthy diet is more & 283 & 89 & 35 & 11
\end{tabular}

Table 8 demonstrates their knowledge on the safety and usefulness of multivitamins. Most of the students [204 (64.4\%)] who participated in the study believed that it is important to consume multivitamin products in our day to day lives: 176 $(56.1 \%)$ participants opinioned that multivitamins are essential for good health. However, only $148(46.5 \%)$ participants were convinced that multivitamins are safe. Figure 6 depicts the knowledge of the participants on multivitamins in general. Based on this chart, it is clearly evident that only a minor percentage of 
students $(17.9 \%)$ have inadequate knowledge about multivitamins. These students mostly belonged to the younger age group studying in first or second years of the medical program. We were able to deduce this result based on the responses of the participants for the questions provided in the "knowledge of multivitamins" section in the questionnaire, which was later analyzed using SPSS program.

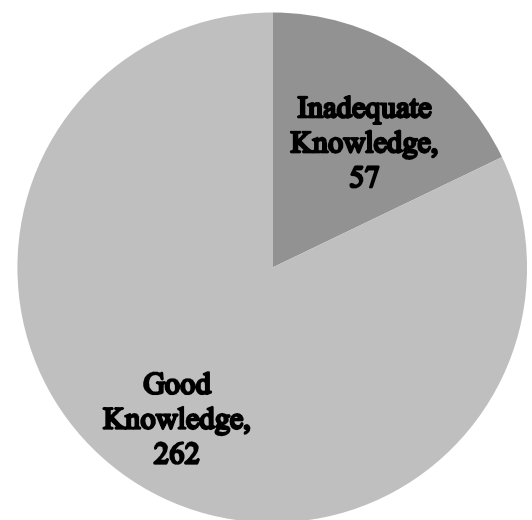

Fig. 6: Distribution of Knowledge of Multivitamins in General among the Students.

Table 8: Participants' Knowledge on the Safety and Utilization of Multivitamins $(\mathrm{N}=319)$.

\begin{tabular}{lcccc}
\hline & \multicolumn{2}{c}{ Yes } & \multicolumn{2}{c}{ No } \\
\cline { 2 - 5 } & No. & \% & No. & \% \\
\hline Important to consume multivitamin products & 204 & 64.4 & 115 & 35.6 \\
Multivitamin are essential for health & 176 & 56.1 & 143 & 43.9 \\
Multivitamin are safe & 148 & 46.5 & 171 & 53.5 \\
\hline
\end{tabular}

\section{DISCUSSION}

This survey was conducted in order to assess the knowledge, attitude and consumption of multivitamins among students. The results of our study revealed that among the 319 participants, $46.5 \%$ (148) used multivitamins. In a similar study conducted in Chandigarh, India, among an adult population, 82 (68.33\%) of the participants were found to use multivitamin supplements (Kaur and Sekhri, 2014). The lower use of multivitamins by students in our study may be because, being from a medical university, they were well informed that in most cases a well-balanced diet was sufficient to meet the body's nutritional requirements and to maintain a healthy state.

In the National Health and Nutrition Examination Survey of 2003-2006, the use of dietary supplements was reported by $53 \%$ of the respondents, of which multivitamins were the most frequently used dietary supplement (Kaur and Sekhri, 2014; Bailey et al., 2011; Gahche et al., 2011). In another survey conducted in Columbia to estimate the use of dietary supplements, $73 \%$ participants were found to be users of dietary supplements and among them, $85 \%$ reported the use of multivitamin supplements (Timbo et al., 2006). Likewise, in a study conducted on 11,929 men in Germany $40 \%$ population reported use of vitamin or mineral supplements (Reinert et al., 2007). Though all the previously mentioned studies report high multivitamin use, in our study less than half the participants $(46.5 \%)$ consumed multivitamin products. The principle source of information about multivitamin products among students in our study was predominantly parents $(53.7 \%)$, followed by internet $(49.9 \%)$, doctors $(45.5 \%)$ and the media $(41 \%)$. A small percentage of $14.6 \%$ and $8.6 \%$ reported that they have heard of multivitamins from the university and other sources respectively. This was unlike the observations of studies conducted in Chandigarh and Karachi where doctors were the most common source of information, (69.1\% and 66.2\%) (Kaur and Sekhri, 2014; Qidwai et al., 2012).

The results of the study conducted in Chandigarh (Kaur and Sekhri, 2014) show that $70.73 \%$ of the users considered multivitamin products to be helpful. When respondents of the Chandigarh study were queried as to whether they had experienced any health problems due to the use of multivitamin products, only one reported diarrhea related to multivitamin use. The majority participants were unaware of the harmful side effects of multivitamin supplements. The results of our study however showed that among the participants who consumed multivitamin products $(46.5 \%), 17.1 \%$ experienced adverse effects on taking the product. Amidst those who had encountered side effects due to multivitamin use, the most commonly reported side effect was stomach pain $(41.7 \%)$ followed by headache $(20.8 \%)$. A small percentage of participants $(16.7 \%)$ reported that they had experienced certain side effects such as constipation, dizziness, diarrhea, dry mouth and indigestion. We also found that of 319 participants of the study, most of them [204 (64.4\%)] believed that it is important to consume multivitamin products in our day to day lives and $176(56.1 \%)$ participants agreed that multivitamins are essential for good health. The findings in our study corroborates with other afore mentioned studies (Kaur and Sekhri, 2014; Bailey et al., 2011; Gahche et al., 2011; Timbo et al., 2006; Reinert et al., 2007; Qidwai et al., 2012). Side effects were experienced by only a minority and may be due improper utilization of multivitamins. Multivitamins products are available in sugar coated or gummy bear formulations to increase their palatability and it may be possible that the adverse effects reported in our study maybe because of excess intake of multivitamins (Kaur and Sekhri, 2014; Block et al., 2007; Huang et al., 2006).

'Several studies ascertain that prolonged use of multivitamins could be hazardous to health and could result in serious long term consequences. These studies include the Alpha-Tocopherol, BetaCarotene Cancer Prevention Study which reported the increased risk of hemorrhagic stroke by $50 \%$ with the use of alpha tocopherol for 6 years (The Alpha-Tocopherol, Beta Carotene Cancer Prevention Study Group, 1994) and the Selenium and vitamin $\mathrm{E}$ cancer prevention trial which revealed that vitamin $\mathrm{E}$ supplements could increase the risk of prostate cancer among healthy men (Lippman et al., 2009; Klein et al., 2011). High doses of vitamin C could result in gastric upset (Gordon and Schaffer, 2005). Therefore, it is pellucid that multivitamins must not be used over long term periods and should be used with caution at the recommended dose.

In our study, the main reasons for the use of multivitamin products were attributed to vitamin D deficiency $(24.7 \%)$ and 
anemia (15.1\%). However in studies conducted by Dickinson et al. ,Neuhouser and Eldridge, and Sheenan, (Dickinson et al., 2011; Neuhouser, 2003; Eldridge and Sheenan, 1994) maintenance of wellness was reported as the top reason for the use of multivitamins (Dickinson et al., 2011). Among 319 students who took part in our survey, $283(89 \%)$ reported that the intake of a balanced diet is sufficient to lead a healthy lifestyle rather than the consumption of multivitamin products. There is no documented evidence that vitamin supplementation is beneficial in people with adequate dietary intake (Briançon et al., 2011).

\section{Limitations of the Study}

As the research was carried out among the students of only one university in the United Arab Emirates, it is not possible to generalize the results. Since, our questionnaire is self-reported, the influence of recall bias is possible. Also, incomplete information related to the socio demographic characteristics and practice of multivitamins had bearing on the results and choice of statistical testing procedures.

\section{CONCLUSION}

Thus it is clearly evident that the results of our study do not coincide with most of the results of different studies conducted on this topic. The reasons for this difference in results could be due to the factors associated with the study population such as age, difference in opinion, etc. People belonging to the general population tend to be comparatively less informed about multivitamins products. Being health conscious, they procure these products enthusiastically based on the information from advertisements and peer advice (Kaur and Sekhri, 2014; Yetley, 2007; Thomas, 2004). In our research, it was identified that the peer influence on the students that convinced them to use multivitamin products was minimal. Also, less number of students preferred using multivitamin products as the felt that the nutrition they obtained from the diet was sufficient for the maintenance of good health.

Finally, as mentioned earlier, there was a significant association between the students' age and knowledge of multivitamins based on the results on Pearson Chi Square Test. Hence, it can be concluded that as the age advanced the knowledge of multivitamins also increased. Therefore, it can be assumed that as the students progressed through the years in the medical university, they became more informed about uses, benefits as well as the adverse effects associated with multivitamins.

Moreover, self-medication is one of the components of self-care adopted by the WHO. Responsible use of OTC medications can help in the prevention and treatment of diseases that do not necessarily need medical consultation and would therefore be a more economical alternative for treatment of common ailments. The challenge before Government bodies and Health Care Authorities is to evolve a framework for responsible use of these medications.
Our results provide additional support for the conclusion that the vast majority of consumers recognize that multivitamins and other supplements can help fill nutrient gaps but should not be viewed as replacements for a healthy diet. These evidences, combined with biological considerations, suggest that any effect, either beneficial or harmful, is probably small. This suggests that policy makers and health professionals could feel comfortable recommending rational dietary supplementation as one means of improving nutrient intakes, without being unduly concerned that such a recommendation would lead consumers to discount the importance of good dietary habits.

\section{ACKNOWLEDGEMENT}

The process of conducting a survey and completing it is indeed a long and arduous process which undeniably cannot be done singlehandedly. First and foremost, I would like to extend my gratitude to Dr. Annie Shirwaikar, our main supervisor and Dr. Arun Shirwaikar (co-supervisor) for their unparalleled support offered to us during the course of the research. I would also like to thank the statistics department of Gulf Medical University, Ajman, UAE for assisting us during the data analysis. Finally, I owe my heartfelt gratitude towards my co researches who worked tremendously hard during the course of this research.

\section{Financial support and sponsorship: Nil.}

Conflict of Interests: There are no conflicts of interest.

\section{REFERENCES}

Bender DA. Daily doses of multivitamin tablets. BMJ, 2002; 325(7357):173-4. [ONLINE] Available at: http://www.ncbi.nlm.nih.gov/pmc/articles/PMC1123707/. [Accessed 07 September 2015].

Bailey RL, Gahche JJ, Lentino CV, Dwyer JT, et al. Dietary supplement use in the United States, 2003-2006. J Nutr. 2011;141:261-6.

Block G, Jensen CD, Norkus EP, Dalvi TB, Wong LG, McManus JF, et al. Usage patterns, health, and nutritional status of longterm multiple dietary supplement users: A cross-sectional study. Nutr J. 2007;6:30.

Briançon S, Boini S, Bertrais S, Guillemin F, Galan P, Hercberg S. Long-term antioxidant supplementation has no effect on health-related quality of life: The randomized, double-blind, placebo-controlled, primary prevention SU.VI.MAX trial. Int J Epidemiol. 2011;40:1605-16.

Drugs.com - Multivitamin (multivitamins) medical facts from

Drugs.com. $2015 . \quad$ Available at: http://www.drugs.com/mtm/multivitamin.html. [Accessed 06 September 2015].

Dickinson A, Shao A, Boyon N, Franco JC. Use of dietary supplements by cardiologists, dermatologists and orthopedists: Report of a survey. Nutr J. 2011;10:20.

El-Kadiki A, Sutton AJ. Role of multivitamins and mineral supplements in preventing infections in elderly people: Systematic review and meta-analysis of randomized controlled trials. BMJ. 2005; 330(7496):871. [ONLINE] Available at: http://www.ncbi.nlm.nih.gov/ pmc/articles/PMC556155/. [Accessed 05 September 2015].

Eldridge AL, Sheenan ET. Food supplement use and related beliefs: survey of community college students. J Nutr Educ. 1994;26:25965. 
Fawzi W, Stampfer MJ. A role for multivitamins in infections? Ann Intern Med. 2003; 138(5):430-1.

Gahche J, Bailey R, Burt V, Hughes J, Yetley E, Dwyer J, et al. Dietary supplement use among U.S. adults has increased since NHANES III (1988-1994) NCHS Data Brief. 2011;61:1-8.

Gordon NP, Schaffer DM. Use of dietary supplements by female seniors in a large Northern California health plan. BMC Geriatr. 2005;5:4.

Hemilä H, Chalker E. Vitamin C for preventing and treating the common cold. Cochrane Database Syst Rev. 2013. Available at: http://www.ncbi.nlm.nih.gov/pubmed/23440782. [Accessed 08 September 2015].

Huang HY, Caballero B, Chang S, Alberg AJ, Semba RD, Schneyer CR, et al. The efficacy and safety of multivitamin and mineral supplement use to prevent cancer and chronic disease in adults: A systematic review for a National Institutes of Health state-of-the-science conference. Ann Intern Med. 2006;145:372-85.

Kaur K, Sekhri K. Public knowledge, use and attitude toward multivitamin supplementation: A cross-sectional study among general public. Int J Appl Basic Med Res. 2014; 4(2): 77-80. [ONLINE] Available at: http://www.ncbi.nlm.nih.gov/pmc/articles/PMC4137646/. [Accessed 04 September 2015].

Kamangar F, Emadi A. Vitamin and mineral supplements: do we really need them? Int J Prev Med. 2012; 3:221-6. [ONLINE] Available at: http://www.ncbi.nlm.nih.gov/pmc/articles/PMC3309636/. [Accessed 04 September 2015].

Klein EA, Thompson IM, Jr, Tangen CM, Crowley JJ, Lucia MS, Goodman PJ, et al. Vitamin E and the risk of prostate cancer: The Selenium and Vitamin E Cancer Prevention Trial (SELECT) JAMA. 2011;306:1549-56.

Lippman SM, Klein EA, Goodman PJ, Lucia MS, Thompson IM, Ford LG, et al. Effect of selenium and vitamin E on risk of prostate cancer and other cancers: The Selenium and Vitamin E Cancer Prevention Trial (SELECT) JAMA. 2009;301:39-51.

McNaughton SA, Mishra GD, Paul AA et al. Supplement use is associated with health status and health-related behaviors in the 1946 British birth cohort. J Nutr. 2005 135:1782-9. [ONLINE] Available at: http://www.ncbi.nlm.nih.gov/pubmed/15987865. [Accessed 04 September 2015].

Munro H, Danford D. Nutrition, aging, and the elderly, human nutrition, a comprehensive treatise. Vol 6. New York: Plenum Press, 1989.

Neuhouser ML. Dietary supplement use by American women: Challenges in assessing patterns of use, motives and costs. J Nutr. 2003;133:1992S-6.

Qidwai W, Samani ZA, Azam I, Lalani S. Knowledge, attitude and practice of vitamin supplementation among patients visiting outpatient physicians in a teaching hospital in Karachi. Oman Med J. 2012;27:116-20

Reinert A, Rohrmann S, Becker N, Linseisen J. Lifestyle and diet in people using dietary supplements: A German cohort study. Eur J Nutr. 2007;46:165-73.
Sebastian RS, Cleveland LE, Goldman JD, Moshfegh AJ. Older adults who use vitamin/mineral supplements differ from nonusers in nutrient intake adequacy and dietary attitudes. J Am Diet Assoc. 2007; 107:1322-32. [ONLINE] Available at: http://www.ncbi.nlm.nih.gov/pubmed/17659898/. [Accessed 04 September 2015]

Sesso HD, Christen WG, Bubes V, Smith JP, MacFadyen J, Schvartz M, et al. Multivitamins in the prevention of cardiovascular disease in men: The Physicians' Health Study II randomized controlled trial. JAMA. 2012; 308:1751-60. [ONLINE] Available at: http://www.ncbi.nlm.nih.gov/pubmed/23117775/. [Accessed 05 September 2015]

Spirichev VB. Scientific rationale for the use of vitamins in the prophylactic and therapeutic purposes. Report 1. Lack of vitamins in the diet of modern human: reasons, consequences and correction. Vopr Pitan. 2010;79(5):4-14. [ONLINE] Available at http://www.ncbi.nlm.nih.gov/pubmed/21341471. [Accessed 06 September 2015]

Timbo BB, Ross MP, McCarthy PV, Lin CT. Dietary supplements in a national survey: Prevalence of use and reports of adverse events. J Am Diet Assoc. 2006;106:1966-74.

The effect of vitamin $\mathrm{E}$ and beta carotene on the incidence of lung cancer and other cancers in male smokers. The Alpha-Tocopherol, Beta Carotene Cancer Prevention Study Group. N Engl J Med. 1994;330:1029-35.

Thomas PR. Supplement use among US adults: Implications for the dietetics professional. J Am Diet Assoc. 2004;104:950-1.

U.S. National Library of Medicine. 2015. Available at: https://www.nlm.nih.gov/. [Accessed 08 September 2015]

Yetley EA. Multivitamin and multimineral dietary supplements: Definitions, characterization, bioavailability, and drug interactions. Am J Clin Nutr. 2007;85:269S-76.

\section{How to cite this article:}

Rosalia R, Panjwani S, Ali AA, Al-Hayali MM, Alahmad AM, Shirwaikar A, Shirwaikar A. A Cross Sectional Survey on the Knowledge and Attitude towards the Use of Multivitamin Products among the Students of a Medical University in the U.A.E. J App Pharm Sci, 2017; 7 (08): 201-208. 